\title{
Ciliary proteins Fap43 and Fap44 interact with each other and are essential for proper cilia and flagella beating
}

\author{
Paulina Urbanska ${ }^{1} \cdot$ Ewa Joachimiak ${ }^{1} \cdot$ Rafał Bazan $^{1} \cdot$ Gang Fu$^{2} \cdot$ Martyna Poprzeczko $\cdot$ Hanna Fabczak ${ }^{1}$. \\ Daniela Nicastro ${ }^{2} \cdot$ Dorota Wloga $^{1}$ (D)
}

Received: 5 December 2017 / Revised: 13 April 2018 / Accepted: 13 April 2018 / Published online: 23 April 2018

(c) The Author(s) 2018

\begin{abstract}
Cilia beating is powered by the inner and outer dynein arms (IDAs and ODAs). These multi-subunit macrocomplexes are arranged in two rows on each outer doublet along the entire cilium length, except its distal end. To generate cilia beating, the activity of ODAs and IDAs must be strictly regulated locally by interactions with the dynein arm-associated structures within each ciliary unit and coordinated globally in time and space between doublets and along the axoneme. Here, we provide evidence of a novel ciliary complex composed of two conserved WD-repeat proteins, Fap43p and Fap44p. This complex is adjacent to another WD-repeat protein, Fap57p, and most likely the two-headed inner dynein arm, IDA I1. Loss of either protein results in altered waveform, beat stroke and reduced swimming speed. The ciliary localization of Fap43p and Fap44p is interdependent in the ciliate Tetrahymena thermophila.
\end{abstract}

Keywords Wdr52 $\cdot$ Wdr65 - Wdr96 $\cdot$ Dyh6 $\cdot$ Dyh7 $\cdot$ Tether/tether head complex

Abbreviations
$\begin{array}{ll}\text { (C)Fap } & \text { (Cilia- and) flagella-associated protein } \\ \text { IDA } & \text { Inner dynein arm } \\ \text { ODA } & \text { Outer dynein arm } \\ \text { WDR } & \text { WD40-repeat }\end{array}$

Paulina Urbanska and Ewa Joachimiak contributed equally to this work.

Electronic supplementary material The online version of this article (https://doi.org/10.1007/s00018-018-2819-7) contains supplementary material, which is available to authorized users.

Dorota Wloga

d.wloga@nencki.gov.pl

Paulina Urbanska

p.urbanska@nencki.gov.pl

Ewa Joachimiak

e.joachimiak@nencki.gov.pl

Rafał Bazan

r.bazan@nencki.gov.pl

Gang Fu

Gang.Fu@UTSouthwestern.edu

Martyna Poprzeczko

m.poprzeczko@nencki.gov.pl

\section{Introduction}

Cilia and their homologous structures, flagella, are evolutionarily conserved organelles that convert the chemical energy released during ATP hydrolysis into a mechanical force to power cell motility or generate fluid flows at the epithelial cell surface. The canonical motile cilium (this term will be used hereafter for both cilia and flagella) consists of a $9+2$ microtubular core, called the axoneme, and multi-subunit complexes, such as the outer and inner dynein arms (ODAs and IDAs), radial spokes (RSs), the nexin-dynein regulatory complex (N-DRC) and the modifier of inner dynein arms (MIA) complex. These complexes

\footnotetext{
Hanna Fabczak

h.fabczak@nencki.gov.pl

Daniela Nicastro

Daniela.Nicastro@UTSouthwestern.edu

1 Laboratory of Cytoskeleton and Cilia Biology, Department of Cell Biology, Nencki Institute of Experimental Biology PAS, Pasteur 3, 02-093 Warsaw, Poland

2 Departments of Cell Biology and Biophysics, University of Texas Southwestern Medical Center, 6000 Harry Hines Blvd., Dallas, TX, USA
} 
are periodically distributed along the outer doublet microtubules and form a characteristic pattern repeating every $96 \mathrm{~nm}$, called the 96-nm axonemal repeat unit [1-3]. Each 96-nm repeat contains four outer and seven inner dynein arms $(\mathrm{a}-\mathrm{g})$ attached to the A-tubule of the outer doublet and extending their motor domains towards the B-tubule of the preceding doublet. In contrast to two-headed (or, in some organisms, three-headed) ODAs, which are periodically distributed every $24 \mathrm{~nm}$ and share similar architecture and protein composition, the IDAs are heterogeneous in their structure and subunit composition, and most likely also in their functions [2, 4-9].

Among IDAs, only the most proximal arm of the 96-nm ciliary unit has a two-headed heterodimeric structure (IDA f or I1), while the remaining six IDAs are single-headed $[2,6]$. The two-headed IDA I1 forms a trilobed structure consisting of two dynein heavy chains that differ in their function and distance from the surface of the A-tubule [6, $10,11]$ and three intermediate and five light chains (ICLC) that form the third lobe [for review, 12, 13]. Cryo-electron tomography and $3 \mathrm{D}$ reconstruction analyses revealed that IDA I1 is highly connected with other axonemal structures [13]. Importantly, the existence of linker structures between outer and inner dynein arms suggests a possible cross-talk between these structures $[2,8,14]$.

The molecular mechanism that regulates cilia and flagella beating is still an intriguing and challenging puzzle. At the ultrastructural level, cilia beating is generated by the spatiotemporally coordinated, ATP-dependent motor activity of the dynein heavy chains of the inner and outer dynein arms. However, a phenotypic analysis of numerous IDA and ODA mutants revealed that inner and outer dynein arms perform different functions and that their activities are regulated differently. It is assumed that the inner dynein arms control the size and waveform of the cilia bend and that their activity is regulated by the mechano-chemical signals initiated at the central pair complex and transmitted to IDAs by the radial spokes. The two-headed IDA I1 is suggested to contribute to the formation of the waveform through the modulation of flagellar bending [9], possibly through changes in the level of phosphorylation of intermediate chain IC138, a subunit of the ICLC structure [4, 15-17]. Interestingly, mutations in IDA I1 can rescue the immotility caused by defects in the cilia central pair complex [5, 18]. In contrast to IDAs, ODAs control the cilia beat frequency and are downstream of IDAs in the signal transduction cascade $[4,7,16,19]$.

The detailed molecular mechanism(s) that regulate(s) cilia beating is/are not fully understood. Among other reasons, this is due to the incomplete identification of the proteins involved in this process and the factors that regulate their interactions, such as second messengers or posttranslational modifications. The assembly and proper function of cilia require several hundred proteins $[20,21]$, but the roles and precise localization (at the ultrastructural level) of a substantial fraction of putative ciliary proteins remain unknown. At the same time, 3D reconstructions using cryoelectron tomography revealed that each axonemal unit contains, in addition to established macromolecular complexes, numerous minor structures of unknown protein composition and function [2, 13, 22-26]. These minor complexes may function as links between the major complexes and/or as their regulators. Some of these minor complexes may even play a role in the regulation of dynein arm activity. Thus, a better understanding of the mechanisms that regulate cilia motility requires the identification of all proteins involved in this process. Despite the substantial progress in localizing and deciphering the roles of new ciliary proteins involved in regulation of cilia beating, such as the recent discoveries of the CSC [27-30] and MIA complexes [3], we are still far from decoding the molecular mechanisms that govern cilia motility.

Here, we present evidence that two highly evolutionarily conserved proteins, Fap43p and Fap44p, localize exclusively to cilia and are indispensable for proper cilia motility in the ciliate Tetrahymena thermophila. Deletion of either Fap43p or Fap44p results in abnormal cilia beating and reduced cell swimming velocity. In cilia, both proteins localize in close proximity to each other and to Fap57p, a large ciliary protein of unknown function, and most likely to IDA I1. Moreover, Fap44p is missing from FAP43-KO mutant cilia, and likewise, Fap43p is absent from cilia lacking Fap44p. Thus, Fap43p and Fap44p are most likely subunits of a minor protein complex that is positioned in close proximity to IDA I1 and may regulate its activity.

\section{Materials and methods}

\section{Strains, culture and phenotypic studies}

The wild-type CU428.2 and B2086.2 cells were obtained from the Tetrahymena Stock Center (Cornell University, Ithaca, NY, US), and the CU522 strain, which carries a mutation in the macronuclear BTU1 locus, causing paclitaxel sensitivity, was kindly provided by Dr. Jacek Gaertig (University of Georgia, Athens, GA, USA). The cells were grown at $30{ }^{\circ} \mathrm{C}$ in SPP (Super Proteose Peptone) medium [31] with moderate shaking ( $80 \mathrm{rpm})$. After transformation by biolistic bombardment, positive clones were selected by growing in SPP medium supplemented with an antibiotic-antimycotic mix (Sigma-Aldrich, St. Louis, MO, USA) and the appropriate selection drug.

The cell proliferation rate, swimming speed and phagocytosis rate were determined as previously described [30]. Cilia motility was visualized in Tetrahymena cells that were partly immobilized in 10\% Ficoll 400 in 10 mM Tris-HCl, 
$\mathrm{pH} 7.5$, in a chamber made on a slide coated with $0.1 \%$ poly-L-lysine [32]; cilia beating was recorded using a highspeed camera (Andor Zyla 5.5 sCMOS) mounted on a Leica DMI 6000 microscope $(63 \times$ oil immersion lens, numerical aperture 1.4) with an Andor DsD2 unit. The frame rate of the video recording was 200 frames/s.

Chlamydomonas fap 44, fap 43 and fap 244 mutants and the control strain (wild-type) cc-4533 were generated by the Chlamydomonas Library Project (CLiP) $[33,34]$ and purchased from the Chlamydomonas Resource Center (http:// www.chlamycollection.org). After streaking the cells on TAP (Tris-Acetate-Phosphate) media agar plates, single colonies were picked and transferred into 24 -well plates with liquid TAP medium and cultured at $23{ }^{\circ} \mathrm{C}$ under $12: 12 \mathrm{~h}$ light/dark conditions.

For genomic DNA analyses, cells were centrifuged at $3000 \mathrm{rpm}$, washed with $\mathrm{ddH}_{2} \mathrm{O}$, and resuspended in 20-50 $\mu \mathrm{l}$ $\mathrm{ddH}_{2} \mathrm{O}$. After the addition of an equal volume of $100 \%$ ethanol and $200 \mu \mathrm{l}$ of 5-10\% (w/v) Chelex-100 (Bio-Rad, CA, USA), the solution was heated for $10 \mathrm{~min}$ at $98{ }^{\circ} \mathrm{C}$. After centrifugation at $10,000 \times g$ for $10 \mathrm{~min}$, the supernatant was used for genotyping (Phire Plant Direct PCR kit, Thermo Fisher Scientific, Waltham, MA, USA) with the following primers: for the fap 44 strain, the gene-specific primer fap44-1 (5'-GAAGGCATAATGGCTGGTGT-3'), inserted cassette primer Aph8-1(5'-GCTCGTGGAGCTCTGAAT CT-3'), and control primers (5'-GAAGGCATAATGGCT GGTGT-3') and (5'-GACGGGCAACGAGTCCTCGC-3'); for the fap 43 strain, the gene-specific primers fap43-1 (5'CTTCAAAAAGGAGTTTGCGG-3') and fap 43-2 (5'-ACA GCCTTGGACCTTCCTTT-3') and control primers (5'-AGC AGCTTCTACCTTCTGCG-3') and (5'-GTGGTGCGGAGA AATGAGAT-3'); and for the fap244 strain, the gene-specific primers fap 244-1 (5'-CACACGTCCATCTGGTTGTC-3') and fap244-2 (5'-GCCATGCTGCTTTCTAGTCC-3') and control primers (5'-GGTATAATGCGGCGTTCTGT-3') and (5'-TCAATCTGTGCCTGCATCTC-3'). For the swimming speed analysis, cells were placed between a glass slide and cover slide separated by a Vaseline cushion, and DIC images of cells were recorded using a $60 \times$ oil objective lens with a Nikon ECLIPSELVDIA-N microscope equipped with an ANDOR Zyla-VSC-04868 camera. Videos ( $400 \mathrm{fps})$ of freely swimming cells were acquired using a $20 \times$ objective and dark-field settings. The motility of cells was tracked with Nikon NIS-Elements AR software, and the swimming speeds were calculated based on the tracked distance and elapsed time. Statistical significance was determined by Student's $t$ test.

\section{Protein tagging and domain analysis}

The Tetrahymena thermophila FAP43 (TTHERM_00196190) and FAP44 (TTHERM_00498220) gene sequences were obtained from the Tetrahymena Genome Database (http://www.ciliate.org). The DNA fragments with the addition of the appropriate restriction sites used to prepare expression plasmids were amplified from the genomic DNA using Phusion Hot Start II high-fidelity DNA polymerase (Thermo Fisher Scientific, Waltham, MA, USA) and the primers listed in Table S1. To express C-terminally 3xHA-tagged Fap43p or Fap44p in their native loci, we used a strategy similar to one described previously [35]. Generally, approximately $1 \mathrm{~kb}$ of the open reading frame (ORF) and $1 \mathrm{~kb}$ of the $3^{\prime} \mathrm{UTR}$ were cloned into an appropriate native locus expression vector [35]. The constructed pFAP43-3HA and pFAP44-3HA plasmids enabled the expression of either Fap43p or Fap44p with the C-terminal 3HA tag under the control of the corresponding native promoter and transcription termination with $0.6 \mathrm{~kb}$ of BTU1 3'UTR. The neo 4 cassette, enabling resistance of the transformed Tetrahymena cells to paromomycin [36], was inserted in the reverse orientation between the $3^{\prime} \mathrm{UTR}$ of BTU1 and the $3^{\prime} \mathrm{UTR}$ of the analyzed gene.

To express Fap43p with a C-terminal GFP tag under the control of its native promoter in the native locus, the 3HA tag from pFAP43-3HA native locus expression plasmids was replaced by a GFP coding region preceded by a 27-nucleotide linker encoding GSGGGSGTG amino acid residues.

To express C-terminally 2V5-tagged Fap43p or Fap44p under the control of their native promoters in their native loci, the 3HA tag from the pFAP43-3HA or pFAP44-3HA native locus expression plasmid was removed and replaced by a $2 \mathrm{~V} 5$ coding region preceded by a 27 -nucleotide linker, and the neo 4 cassette was replaced by a cassette providing resistance of the transformed Tetrahymena cells to puromycin [37]. The pFAP57A-2V5 native locus expression plasmid was generated by replacing the FAP44 gene fragment in the pFAP44-2V5 native locus expression plasmid with a fragment of the open reading frame and 3'UTR fragment of FAP57A, amplified using primers listed in Table S1.

To express C-terminally HA-BirA*-tagged Fap43p or Fap44p under the control of their native promoter in the native loci, the 3xHA tag from the pFAP43-3HA or pFAP44-3HA native locus expression plasmids was removed and replaced by a Tetrahymena-optimized BirA* coding region (kindly provided by Dr. Jacek Gaertig) preceded by a 27-nucleotide linker encoding the amino acid residues GSGGGSGTG and a single HA coding region.

Approximately $10 \mu \mathrm{g}$ of the final plasmid was digested with $M l u \mathrm{I}$ and $X h o \mathrm{I}$ to separate the targeting fragment from the plasmid backbone, precipitated onto DNAdel Gold Carrier Particles (Seashell Technology, La Jolla, CA, USA) according to the manufacturer's instructions and biolistically transformed into CU428.2 cells or mutant cells. Transformants were selected for $3-4$ days at $30{ }^{\circ} \mathrm{C}$ on SPP 
with $2.5 \mu \mathrm{g} / \mathrm{ml} \mathrm{CdCl}{ }_{2}$ and either $100 \mu \mathrm{g} / \mathrm{ml}$ paromomycin (BioShop Canada Inc.) or $200 \mu \mathrm{g} / \mathrm{ml}$ puromycin (BioShop Canada Inc.) The positive clones were grown in media with decreasing concentrations of $\mathrm{CdCl}_{2}$ (to $0.05-0.1 \mu \mathrm{g} / \mathrm{ml}$ ) and either an increasing concentration of paromomycin or a constant concentration of puromycin to promote phenotypic assortment.

To overexpress Fap43p, the predicted ORF of FAP43 was amplified with the addition of $M l u \mathrm{I}$ and BamHI sites at the 5' and $3^{\prime}$ ends, respectively (primers in Table S1), and cloned into either the pMTT1-GFP vector [38] or the pMTT1-HA vector [30], enabling protein expression as an N-terminally GFP- or HA-tagged fusion protein under the control of a cadmium-dependent $M T T 1$ promoter from a non-essential BTU1 locus. To overexpress Fap44p in its native locus, approximately $1.2 \mathrm{~kb}$ of the predicted ORF of FAP44, starting from the ATG codon, was amplified with the addition of MluI and BamHI sites at the 5' and 3' ends, respectively, and cloned into a pMTT1-GFP vector [38]. Next, the 5'UTR BTU1 fragment was removed using SacII and ClaI sites and replaced by $0.8 \mathrm{~kb} 5^{\prime} \mathrm{UTR}$ of FAP44, amplified with the addition of SacII and PstI sites at the $5^{\prime}$ and $3^{\prime}$ ends, respectively, and a neo 2 cassette [39], amplified with the addition of PstI and ClaI sites. Thus, the neo 2 cassette was inserted in the reverse orientation between the 5'UTR of FAP44 and the MTT1 promoter. The transgene was separated from the plasmid backbone using SacII and BamHI.

For domain truncation analyses, fragments of the FAP43 or FAP44 ORFs were amplified with the addition of the MluI and BamHI restriction sites (primers in Table S1) and cloned into a pMTT1-HA plasmid to enable the expression of protein with C-terminal HA tag [40].

Approximately $15-20 \mu \mathrm{g}$ of the obtained plasmid was digested with ApaI and SacII to separate the constructs from the plasmid backbone and used to biolistically transform CU522 cells. The transformed cells were selected for 3-4 days on SPP medium supplied with $20 \mu \mathrm{M}$ paclitaxel (BioShop Canada Inc.).

\section{Deletion of Tetrahymena FAP43 and FAP44 gene fragments}

A construct to disrupt the FAP43 coding region was prepared using a pNeo4 plasmid [36]. Briefly, two fragments of the gene, separated by $0.62 \mathrm{~kb}$, were amplified by PCR with the addition of ApaI and SmaI sites for the upstream $1.77 \mathrm{~kb}$ fragment and PstI and SacII restriction sites for the $1.52 \mathrm{~kb}$ downstream fragment and cloned into a pNeo4 plasmid such that the neo4 cassette was in reverse orientation to FAP43 (primers in Table S1). For biolistic transformation of the conjugating CU428.2 and B2086.2 cells, $60 \mu \mathrm{g}$ of the obtained plasmid was digested with ApaI and SacII restriction endonucleases and coated onto gold particles.
The conjugating cells $\left(10^{7}\right.$ cells $)$ were transformed with three shots $(20 \mu \mathrm{g}$ per shot). The FAP43 heterokaryons were generated as described [41, 42]. The deletion of the $0.62-\mathrm{kb}$ fragment of the FAP43 gene was confirmed by PCR with the primers listed in Table S1.

To engineer cells lacking a fragment of FAP43, FAP44, DYH6 or $D Y H 7$ in the macronuclear genome, a $0.6-1-\mathrm{kb}$ fragment encompassing a part of the 5'UTR and ORF of the gene was amplified by PCR with the addition of pcoDel plasmid flanking sequences [43] and cloned into a pcoDel plasmid (kindly provided by Dr. Mochizuki) digested with NotI using the Gibson method [44] and the OverLap Assembly Kit (A\&A Biotechnology, Poland). A $10 \mu \mathrm{g}$ sample of the obtained FAP43, FAP44, DYH6 or DYH7 coDel plasmid was used to biolistically transform the conjugating CU428.2 and B2086.2 cells, and transformants were selected for 3-4 days on SPP medium supplied with $100 \mu \mathrm{g} / \mathrm{ml}$ paromomycin. Among the paromomycin-resistant clones, cells from slow-swimming clones (suggesting defects in cilia function) were selected, and the targeted loci were analyzed by PCR [43]. The genomic DNA was purified, and the size of the deleted fragment was estimated by PCR using primers complementary to the genomic sequences positioned approximately $1 \mathrm{~kb}$ upstream and $1 \mathrm{~kb}$ downstream of the fragment inserted into a pcoDel plasmid. The PCR product was sequenced to confirm deletion of the fragment of the gene. To confirm that the selected gene was specifically targeted in the coDel mutant cells, mutants were rescued with a 3-kb PCR fragment encompassing the deleted sequences, and phenotypic analyses of the rescued cells were performed.

\section{Immunofluorescence and western blot analysis}

The cells were fixed and stained on coverslips as previously described [30,35]. The antibodies were used in the following final concentrations: monoclonal mouse anti-HA antibodies (Covance, Berkeley, CA) 1:300, polyclonal rabbit anti-HA antibodies (Cell Signaling Technology, Danvers, MA) 1:300, monoclonal rabbit anti-V5 antibodies (Cell Signaling Technology, Danvers, MA) 1:1600, polyclonal rabbit anti-GFP antibodies (Abcam, Cambridge, UK) 1:6000, anti- $\alpha$-tubulin 12G10 antibodies (Developmental Studies Hybridoma Bank, Iowa University, Iowa City, IA, USA) 1:300, anti-mouse IgG Alexa-488 or anti-mouse IgG Alexa-555 antibodies (Invitrogen, Eugene, OR, USA) 1:300. After washing, the coverslips were mounted in Fluoromount-G (Southern Biotech, Birmingham, AL, USA) and viewed using a Zeiss LSM780 or a Leica TCS SP8 confocal microscope.

For western blots, cells were grown in SPP with shaking $(80 \mathrm{rpm})$ at $30{ }^{\circ} \mathrm{C}$ and deciliated as previously described [45]. Cilia proteins $(20 \mu \mathrm{g})$ were run on a $10 \%$ SDS-PAGE gel and transferred to a nitrocellulose membrane. After an hour of blocking with 5\% non-fat milk in TBS, the 
membrane was incubated overnight at $4{ }^{\circ} \mathrm{C}$ with one of the following primary antibodies diluted in $1 \%$ non-fat milk in TBS: anti-HA (1:2000), anti-V5 (1:1600), or anti-GFP $(1: 60,000)$. After washing for $3 \times 15 \mathrm{~min}$ in TBS-Tween 20 , followed by a single wash in TBS, the membrane was incubated with secondary antibodies, either anti-mouse IgG-HRP or anti-rabbit IgG-HRP (Jackson ImmunoResearch, West Grove, PA), diluted 1:20,000 in 1\% non-fat milk for $1.5 \mathrm{~h}$ at RT. After washing in TBS-Tween 20 $(3 \times 15 \mathrm{~min})$ and TBS $(15 \mathrm{~min})$, proteins were detected using a Westar Supernova kit (Cyanagen, Italy).

\section{Mass spectrometry analyses}

To identify proteins that co-immunoprecipitate with GFPtagged Fap43p, the cytoskeletal fraction [46] or cilia from Tetrahymena cells overexpressing GFP-Fap43p or expressing Fap43p-GFP, respectively, and GFP-expressing cells (negative control) were harvested and processed as previously described [30]. To identify potential Fap43p or Fap44p-interacting proteins using proximity-dependent labeling, cells expressing either Fap43p-HA-BirA* or Fap44p-HA-BirA* were grown in SPP medium to a density of $2 \times 10^{5}$ cells $/ \mathrm{ml}$, starved overnight in $10 \mathrm{mM}$ Tris-HCl buffer, $\mathrm{pH} 7.5$, and incubated in the same buffer supplied with $50 \mu \mathrm{M}$ biotin for $2-4 \mathrm{~h}$ at $30{ }^{\circ} \mathrm{C}$. After deciliation [45], the collected cilia were resuspended in $0.5 \mathrm{ml}$ of axoneme stabilization buffer $(20 \mathrm{mM}$ potassium acetate, $5 \mathrm{mM} \mathrm{MgSO}_{4}, 20 \mathrm{mM}$ HEPES, $0.5 \mathrm{mM}$ EDTA) and treated for $5 \mathrm{~min}$ on ice with $10 \mu \mathrm{l}$ of $10 \%$ NP-40 to remove the ciliary membrane. After centrifugation (10 min at $21,100 \times g$ at $\left.4{ }^{\circ} \mathrm{C}\right)$, the axonemes were resuspended in a lysis buffer $(50 \mathrm{mM}$ Tris-HCl, pH 7.4, $500 \mathrm{mM} \mathrm{NaCl}$, $0.4 \%$ SDS, $1 \mathrm{mM}$ DTT), incubated at RT for $1 \mathrm{~h}$, and then centrifuged at $8000 \times g$ at $4{ }^{\circ} \mathrm{C}$. The collected supernatant was diluted with an equal volume of $50 \mathrm{mM}$ Tris- $\mathrm{HCl}$ buffer, $\mathrm{pH} 7.4$, and incubated overnight with $100 \mu \mathrm{l}$ of streptavidin-coupled Dynabeads (Dynabeads ${ }^{\mathrm{TM}} \mathrm{M}-280$ Streptavidin, Thermo Fisher Scientific, Waltham, MA, USA) at $4{ }^{\circ} \mathrm{C}$. After washing $(6 \times 5$ min with washing buffer: $15 \mathrm{mM}$ Tris-HCl, pH $7.4150 \mathrm{mM} \mathrm{NaCl}, 0.1 \%$ SDS, $0.3 \mathrm{mM}$ DTT) at $4{ }^{\circ} \mathrm{C}$, resin-bound proteins were analyzed on SDS-PAGE gel, followed by western blot with anti-streptavidin-HRP (Thermo Scientific, Rockford, IL, USA), diluted 1:40,000, or by mass spectrometry (Laboratory of Mass Spectrometry, Institute of Biochemistry and Biophysics, PAS, Warsaw, Poland).

For the entire cilia proteome, wild-type and mutant cells were deciliated as above, the cilia were collected and washed

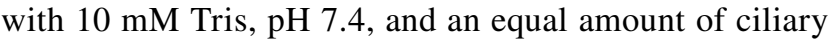
protein was run on SDS-PAGE gel and analyzed by mass spectrometry (Laboratory of Mass Spectrometry, Institute of Biochemistry and Biophysics, PAS, Warsaw, Poland).

\section{Phylogenetic analysis}

Fap43p and Fap44p orthologs were identified in the NCBI protein database using Blastp search and either Tetrahymena or Chlamydomonas protein as bait. Protein amino acid sequences were aligned using the ClustalX2 program [47] and edited using the SeaView program [48]. The predicted protein sequence of Chlamydomonas Fap43p was manually corrected as described in the legend of Fig. S1. The domain analyses were performed using SMART (http:// smart.embl-heidelberg.de/), WDSP (http://wu.scbb.pkusz .edu.cn/wdsp), [49-51] and COILS (http://www.ch.embne t.org) [52] programs.

\section{Results}

\section{Knockout of FAP43 reduces cilia beating amplitude}

The bioinformatics screen of the human ciliome against Tetrahymena thermophila and Arabidopsis thaliana proteomes enabled the selection of numerous highly evolutionarily conserved and yet uncharacterized putative ciliary proteins. Among them, our attention was drawn to the Tetrahymena ortholog of Chlamydomonas reinhardtii Fap43p and the human protein Wdr96p (WD-repeat protein 96). The phylogenetic screen showed that Fap43p/Wdr96p orthologs are present in organisms that assemble motile cilia but not in the worm C. elegans, which forms only immotile sensory cilia (Fig. S1).

Tetrahymena Fap43p is a 1678-amino acid protein with a calculated molecular weight of $198 \mathrm{kDa}$. Similar to other Fap43p orthologs, this protein contains two structurally distinct regions: a WD40-repeat-rich $\mathrm{N}$-terminal region and a C-terminal region predicted to form coiled coils (Fig. S2a). When expressed under the control of the native promoter, Fap43p-3HA was exclusively targeted to cilia and was present along the entire length of the cilium, with the exception of the cilium tip (Fig. 1a-c'). Two closely co-migrating bands of Fap43p were detected in a western blot analysis of the ciliary proteins isolated from Fap43p-3HA-expressing cells (Fig. 1d). Because alternative splicing is infrequent in Tetrahymena cells $[53,54]$, it is most likely that Fap43p is posttranslationally modified.

To identify the region(s) of Fap43p required for its ciliary localization, we overexpressed either full-length Fap43p or the truncated variants of the protein (Fig. S2a-b) under the control of a cadmium-inducible MTT1 promoter [55] from a non-essential BTU1 locus. When overexpressed, full-length Fap43p localized to cilia, and the excess of the 

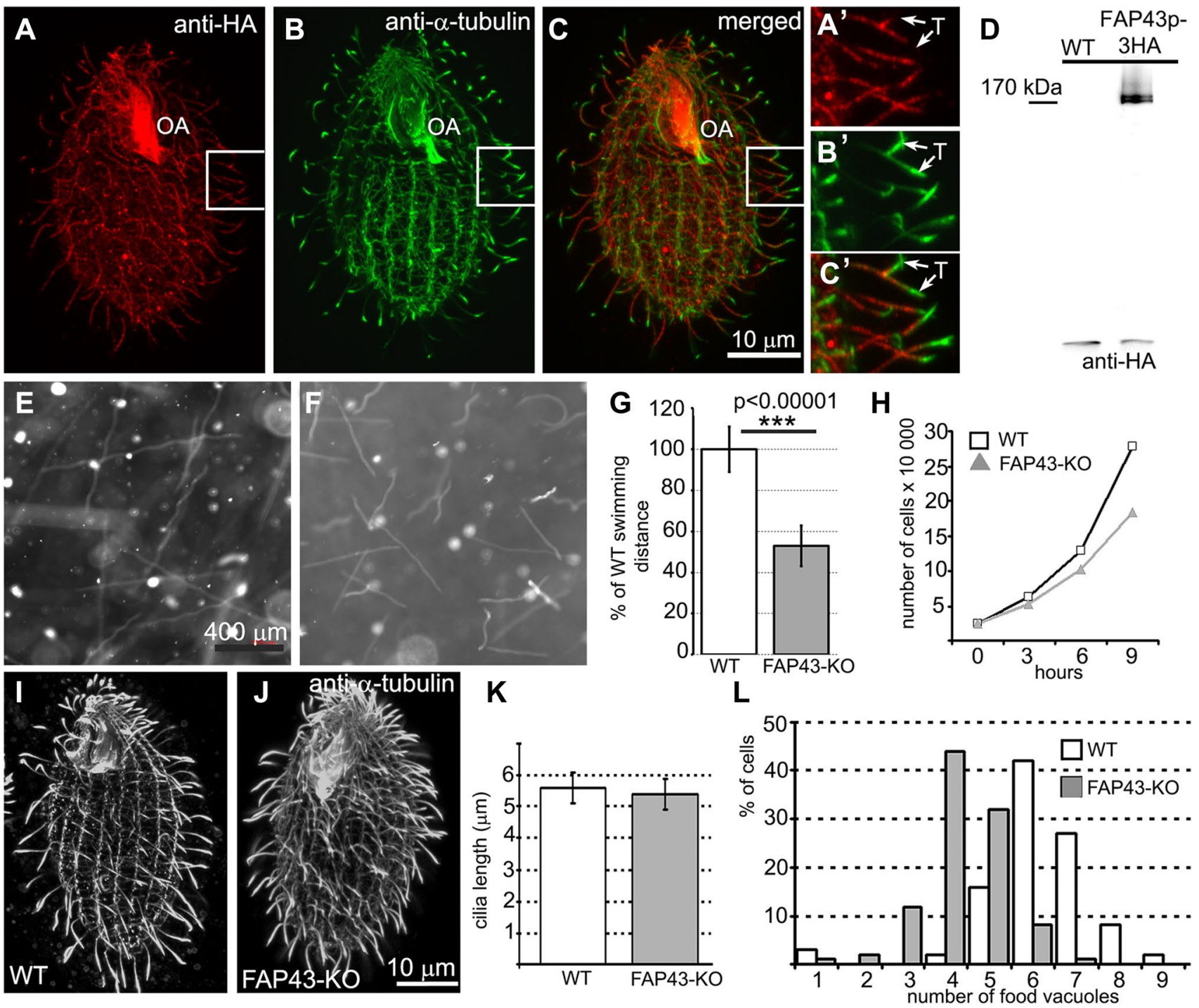

Fig. 1 Fap43p-3HA localized throughout the cilia except at the cilia tips, and knockout of FAP43 affects cilia function but not cilia length in Tetrahymena cells. a-c' Immunofluorescence confocal images of Tetrahymena cells expressing Fap43p-3HA at the native level, double labeled with anti-HA $\left(\mathbf{a}, \mathbf{a}^{\prime}\right)$ and anti- $\alpha$-tubulin antibodies $\left(\mathbf{b}, \mathbf{b}^{\prime}\right)$. c, $\mathbf{c}^{\prime}$ Merged images. $\mathbf{a}^{\prime}, \mathbf{b}^{\prime}, \mathbf{c}^{\prime}$ The magnification of cilia marked with white insets in $\mathbf{a}, \mathbf{b}$, and $\mathbf{c}$, respectively. $O A$ oral apparatus, $T$ cilium tip. Scale bar $10 \mu \mathrm{m}$. d Western blot analysis of the ciliary proteins isolated from wild-type and Fap43p-3HA-expressing cells. Note the presence of two HA-positive bands. Swimming paths of wild-type (e) and FAP43 knockout cells (f) recorded for $3.2 \mathrm{~s}$ using a video camera. g Average distance swum during $3.2 \mathrm{~s}$, normalized to the

expressed protein accumulated near the basal bodies (Fig. S2c-c'). Similar localization was observed in cells that overexpressed the C-terminal fragment of Fap43p, which is predicted to form coiled-coils (Fap43p G667-Y1678, Fig. S2d). In contrast, the N-terminal fragment, containing only WD40 repeats (M1-K712), was most likely unstable or toxic, as it was maintained in the cytoplasm at a very wild-type value (WT $n=139, F A P 43-K O \quad n=146$ ). Bars represent standard deviation, $p$ value $<0.00001$. h Growth curves of wild-type and FAP43 knockout cells. Deletion of Fap43p does not affect cilia length. Immunofluorescence confocal images of wild-type (i) and FAP43 knockout cells (j) stained with anti- $\alpha$-tubulin antibodies. Scale bar $10 \mu \mathrm{m}$. (k) Graphical representation of wild-type $(n=130)$ and FAP43 knockouts $(n=50)$ cilia length measurements. Bars represent standard deviation. 1 Graph showing the efficiency of the formation of food vacuoles based on the analyses of the number of India inkfilled food vacuoles per cell formed during $10 \mathrm{~min}$. On average, wildtype and FAP43-KO cells formed 5.1 vacuoles $(n=406$ cells) and 3.3 vacuoles $(n=344)$, respectively

low level (Fig. S2e). However, a fragment containing both the WD40 repeats and the subsequent three out of seven domains predicted to form coiled-coils, although prone to degradation (Fig. S2b), was detected at a low level in the cilia and cell cortex (Fig. S2f). Thus, the C-terminal fragment is indispensable and sufficient for ciliary localization of Fap43p. 
To learn about the role of the protein, we generated FAP43 germline knockout cells (FAP43-KO, Fig. S3). Compared to wild-type cells, Tetrahymena mutants lacking Fap43p exhibited a phenotype typical of cells with ciliary defects, including reduced cell swimming speed, proliferation rate and phagocytosis rate. The video recording of live cells showed that FAP43-KO cells swam with significantly reduced velocity and on average traveled half the distance $(53 \pm 10 \%)$ traveled by wild-type cells (Figs. 1e-g, 2a, Fig. S4, Supplemental Movies 1 and 2). In the ciliate Tetrahymena, cilia beating contributes to the separation of two daughter cells during the final stage of cell division [56]. Accordingly, cells lacking Fap43p multiplied more slowly than wild-type cells (Fig. 1h). The calculated doubling time of the FAP43 knockouts was approximately an hour longer than that of wild-type cells (wild-type-2.4 h, FAP43$K O-3.5 \mathrm{~h}$ ). Near the cell anterior, Tetrahymena cells form an oral apparatus, a funnel-like structure surrounded by four rows of ciliated basal bodies. During phagocytosis, funneling of the food particles to the oral cavity depends upon the synchronous beating of oral cilia [57]. Cells lacking Fap43p formed fewer food vacuoles than did wild-type cells, as was visualized by growing cells in a medium supplemented with India ink (Fig. 11).

Immunofluorescence light microscopy with anti- $\alpha$-tubulin antibodies revealed that $F A P 43-K O$ cells assemble cilia in similar number and length as wild-type cells (Fig. 1i-k).
Therefore, the reduced efficiency of cilia-related processes was most likely caused by impaired ciliary motility. Therefore, we used a high-speed camera to record cilia beating in wild-type and mutant cells. In the wild-type cells, cilia beat synchronously, with well-defined phases of the power and recovery strokes that take place in different beating planes (Fig. 2b, Fig. S5, Supplemental Movie 3). During the power stroke phase, cilia are stiff and stroke in the direction of the cell posterior end, marking a semicircle perpendicular to the cell surface. During the recovery phase, cilia bend and move parallel to the cell surface, returning to the initial position with their tips facing the cell anterior end. In FAP43 knockouts, the waveform of the cilia beat was altered; the extent of the strokes was approximately half that of the control, and the cilia were more perpendicular to the cell surface at the beginning and end of each beat cycle (Fig. 2b, Fig. S5, Supplemental Movie 4). Although some cilia started the power stroke and finished the recovery stroke closer to the cell surface, the beating amplitude remained smaller than that in wild-type cells.

\section{Fap43p interacts with Fap44p, and their localization to cilia is interdependent}

Because classical transmission electron microscopy analysis did not reveal any apparent changes in the ultrastructure of the axoneme of FAP43 knockouts (data not shown),
Fig. 2 Comparison of the motility and ciliary waveform of wild-type and Tetrahymena mutants. a Graph representing distances with standard deviation swam during $3.2 \mathrm{~s}$ by wild-type $(\mathrm{WT}, 849 \pm 120 \mu \mathrm{m}$, $n=117)$, DYH6coDel $(381 \pm 55 \mu \mathrm{m}, n=79), D Y H$ $7 \mathrm{coDel}(346 \pm 73 \mu \mathrm{m}, n=89)$, FAP43-KO $(469 \pm 88 \mu \mathrm{m}$, $n=84)$, FAP43coDel

$(473 \pm 84 \mu \mathrm{m}, n=100)$, FAP44coDel $(435 \pm 81 \mu \mathrm{m}$, $n=100)$, DYH6coDel rescued $(833 \pm 120 \mu \mathrm{m}, n=90), \mathrm{DYH}-$ 7 coDel rescued $(814 \pm 104 \mu \mathrm{m}$, $n=81)$. $N$ number of measured paths. b Drawings representative of tracing of the power (red) and recovery (green) stroke of a single cilium: wildtype, FAP43-KO, FAP44 coDel, DYH6 coDel and DYH7 coDel. Drawings were prepared based on the images selected from high-speed videos (Fig. S5 and supplemental Movies)
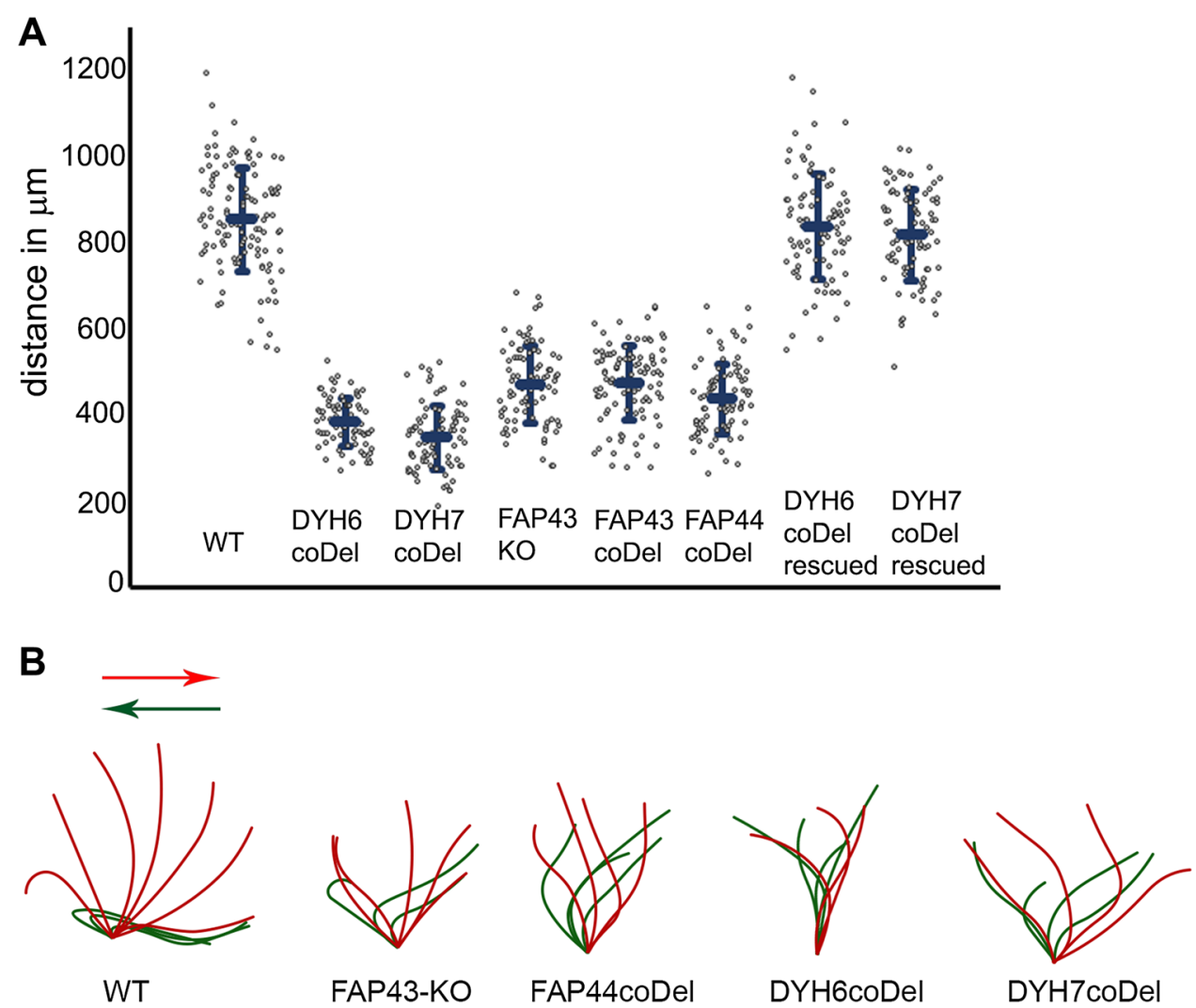
to address the question of Fap43p localization and function in cilia, we searched for Fap43p-interacting proteins using two biochemical approaches. First, we immunoprecipitated GFP-tagged Fap43p from either ciliary or cytoskeletal fractions isolated from cells expressing Fap43p-GFP at the native level or overexpressing GFP-Fap43p, respectively, using anti-GFP antibodies and analyzed the immunoprecipitates by mass spectrometry. The corresponding fractions isolated from cells expressing the GFP protein alone were used as controls (Fig. S6a-b). The comparison of the experimental and control immunoprecipitates indicated that Fap43p and an ortholog of Chlamydomonas Fap $44 p$ were absent in the controls but predominant among the proteins identified in immunoprecipitates from cells expressing GFP-tagged Fap43p (Table 1, Tables S2, S3).

When overexpressed, GFP-Fap43p immunoprecipitated not only with Fap44p but also with three nucleoporins (Nup93, Nup155 and Nup308), kinesin type II and dynein heavy chains of the outer dynein arms (Table S2). However, the number of Fap43p- and Fap44p-specific peptides was significantly higher than the number of peptides of the other co-precipitated proteins (Table S2). Because the majority of the overexpressed GFP-Fap43p accumulates near the basal bodies (Fig. S2c), and because nucleoporins and outer arm dyneins were not identified as potential Fap43p partners when Fap43p was expressed at the native level and purified from cilia (Table 1, Tables S3, S4), we suspect that these proteins are not true Fap43p interactors.
Because of the limitations of the co-IP approach, we next took advantage of the BirA* proximity labeling assay, which enables the identification of potential interactors that are within $10 \mathrm{~nm}$ of the target [58]. We isolated cilia from either wild-type Tetrahymena cells or cells expressing Fap43p-HA-BirA* under the control of a FAP43 promoter, both grown for $4 \mathrm{~h}$ in a medium supplied with $0.05 \mathrm{mM}$ biotin. The biotinylated proteins (Fig. S6c) were purified using streptavidin-coated beads and analyzed by mass spectrometry. In addition to Fap43p and Fap44p, we repeatedly identified three orthologs of Chlamydomonas Fap57p, with one ortholog, Fap57Ap, predominating (Table 1, Table S4).

The reciprocal experiment with cilia isolated from cells expressing C-terminally BirA*-tagged Fap44p (Fig. S6d) strengthens the hypothesis that Fap43p, Fap44p and Fap57p are positioned in close proximity in the Tetrahymena axoneme (Table 1, Table S5). Interestingly, the ratio of the Fap57p peptides to either the Fap43p or Fap44p peptides was higher if Fap44p was tagged with BirA* ligase (Table 1). Thus, it is very likely that the C-terminal end of Fap44p is positioned closer to Fap57p than is the C-terminal end of Fap43p. A few peptides of Dyh6p, the dynein heavy chain of the two-headed inner dynein arm IDA I1, were also identified in Fap43p-HA-BirA* and Fap44p-HA-BirA* precipitates (Table 1).

Fap44p and Fap57Ap, the orthologs of human Wdr52 and $\mathrm{Wdr65}$, respectively, are large, previously uncharacterized
Table 1 Mass spectrometry analysis of proteins co-immunoprecipitated with GFP-tagged Fap43p or biotinylated in cells expressing either Fap43-HA-BirA* or Fap44-HA-BirA*

\begin{tabular}{llllll}
\hline Protein & Total number of peptides & & & \\
\cline { 2 - 6 } & Number in TGD & GFP-Fap43p-oex & $\begin{array}{l}\text { Fap43p-GFP } \\
\text { native }\end{array}$ & $\begin{array}{l}\text { Fap43p- } \\
\text { BirA* native }\end{array}$ & $\begin{array}{l}\text { Fap44p- } \\
\text { BirA* } \\
\text { native }\end{array}$ \\
\hline Fap43 & TTHERM_00196190 & $682 / 454$ & $12 / 7$ & $74 / 52$ & $32 / 18$ \\
Fap44 & TTHERM_00498220 & $215 / 188$ & $13 / 9$ & $57 / 37$ & $31 / 18$ \\
Fap57A & TTHERM_00105300 & 0 & 0 & $31 / 19$ & $56 / 30$ \\
Fap57B & TTHERM_00052490 & 0 & 0 & $6 / 4$ & $3 / 2$ \\
Fap57C & TTHERM_00214710 & 0 & 0 & $3 / 3$ & $4 / 3$ \\
Dyh6 & TTHERM_00688470 & 0 & 0 & $1 / 1$ & $2 / 2$ \\
Dyh7 & TTHERM_00912290 & 0 & 0 & 0 & 0 \\
Dyh3 & TTHERM_01276420 & $10 / 10$ & 0 & $1 / 1$ & $0 / 0$ \\
Dyh4 & TTHERM_00499300 & $11 / 11$ & 0 & $2 / 2$ & $2 / 2$ \\
Dyh5 & TTHERM_00486600 & $15 / 15$ & 0 & $0 / 0$ & $0 / 0$ \\
\hline
\end{tabular}

In the corresponding control samples, the proteins listed in the table were not identified. Note that the number of identified peptides of Fap43p and Fap44p is significantly larger than the number of peptides of other proteins. In Tetrahymena cells, the excess of the overexpressed GFP-Fap43p accumulates near the basal bodies (Fig. S2). Co-precipitation of ODA dynein heavy chains in cells overexpressing GFP-Fap43p is likely due to their accumulation at the cilia base before transport to the cilia (in the case of overexpressed GFP-Fap43p, the cytoskeletal fraction was analyzed). Note that only 1-2 peptides of Dyh3p and Dyh4p were detected in samples prepared from cells expressing either Fap43p or Fap44p at the native level (similar to the number of the Dyh6 peptides; however, in contrast to IDA I1, there are four ODAs in each axonemal unit). All proteins identified in the experimental and control samples are listed in Tables S2-S5 

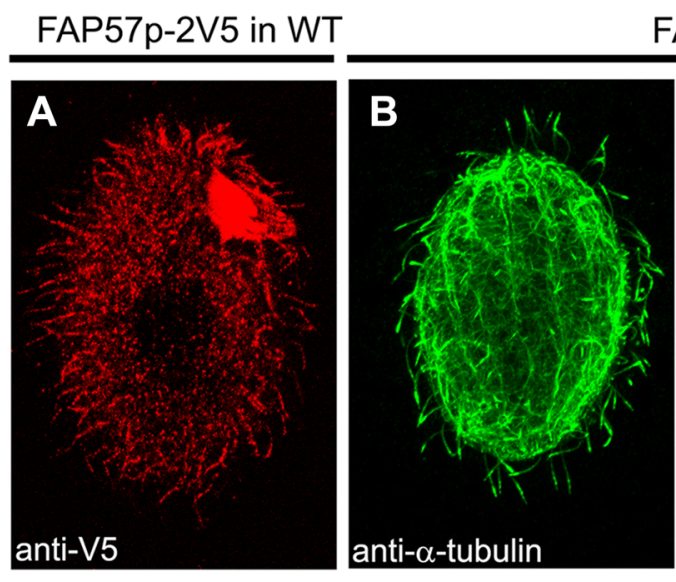

FAP57p-2V5 in FAP43-KO
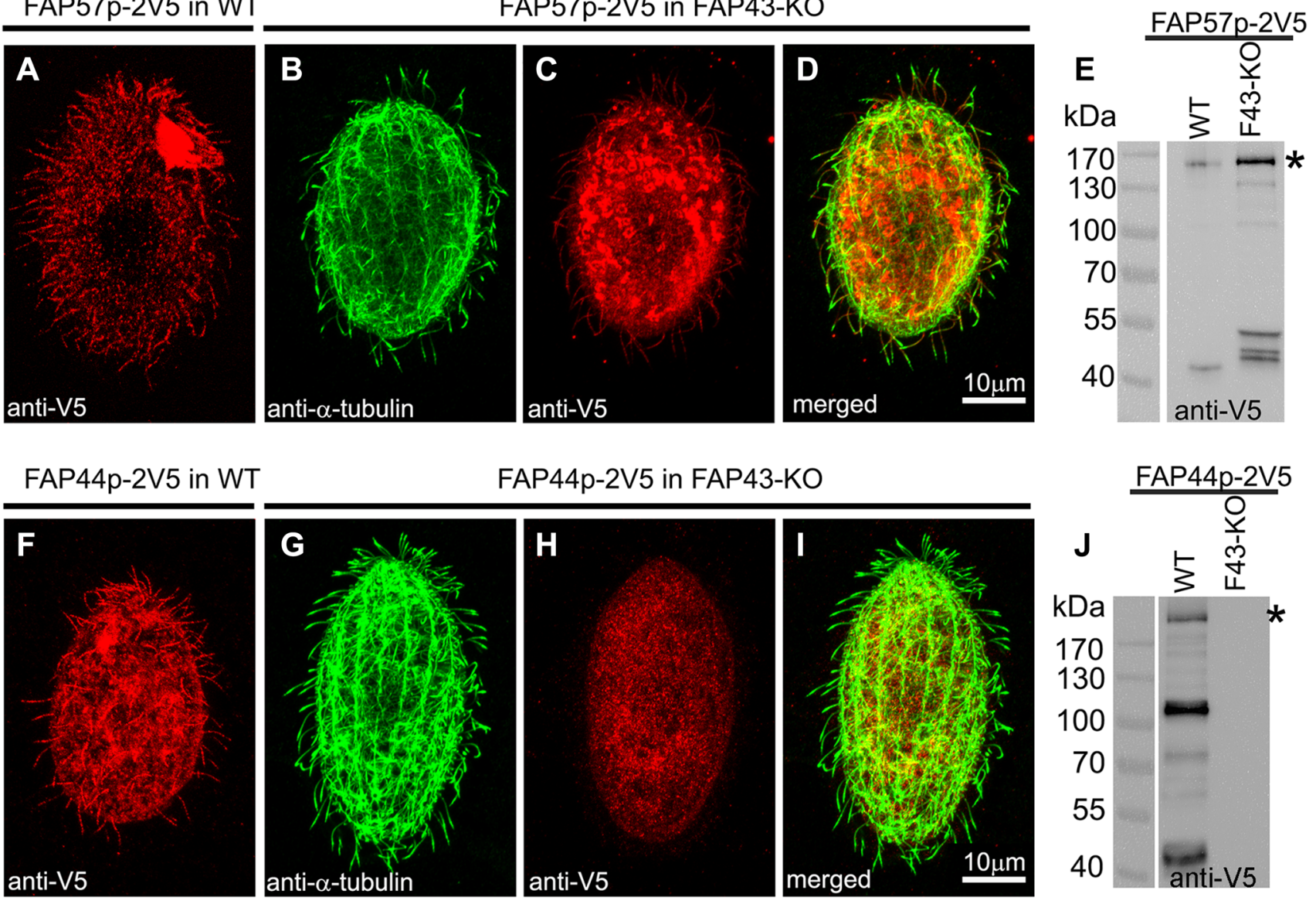

FAP44p-2V5 in FAP43-KO
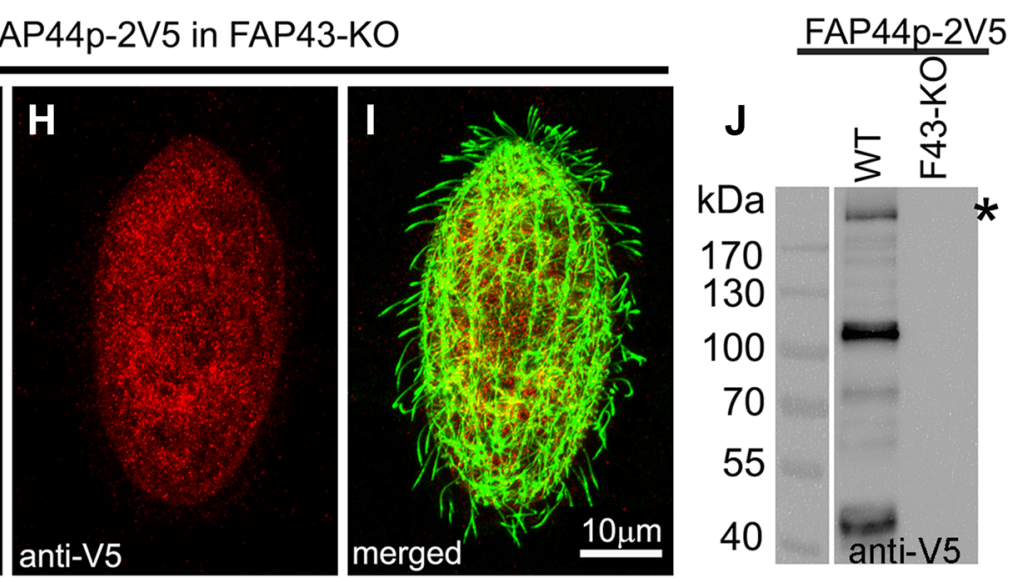

Fig. 3 Fap43p is indispensable for Fap44p but not Fap57p ciliary localization. a-d, $\mathbf{f}-\mathbf{i}$ Immunofluorescence confocal images of either wild-type (a, f) or FAP43-KO Tetrahymena cells (b-d, $\mathbf{g - i}$ ) expressing either Fap57p-2V5 (a-d) or FAP44p-2V5 (f-i) under the control

ciliary proteins with calculated molecular weights of 215 and $152 \mathrm{kDa}$, respectively (Figs. 3a, e, f, j, 4a-d). Both proteins are evolutionarily conserved in organisms assembling motile cilia or flagella (Figs. S7, S8). Their N-terminal fragments are enriched in WD repeats, while the C-terminal regions contain coiled-coil domains (Figs. S9a, e). Thus, the domain compositions of Fap44p and Fap57p are similar to that of Fap43p. Moreover, similar to Fap43p, the HAtagged C-terminal fragment of Fap44p containing coiledcoil domains was necessary and sufficient for its ciliary localization, while the WD-repeat-rich N-terminal fragment accumulated in the cell body (Fig. S9b-d).

Next, we analyzed whether the ciliary localization of Fap44p and Fap57p depends upon the presence of Fap43p. We prepared constructs enabling the expression of $2 x \mathrm{~V} 5$ tagged Fap $44 p$ or Fap57p under the control of the respective native promoters and used these to transform either wildtype (control) or mutant cells lacking Fap43p. The immunofluorescence analysis showed that Fap57p-2V5 expressed at the native level was targeted to cilia in both wild-type of their native promoters, double labeled with anti-V5 $(\mathbf{a}, \mathbf{c}, \mathbf{f}, \mathbf{h})$ and anti- $\alpha$-tubulin antibodies $(\mathbf{b}, \mathbf{g})$. d, i Merged images. Western blot analysis of ciliary proteins isolated from wild-type and FAP43-KO cells expressing either Fap57p-2V5 (e) or Fap44p-2V5 (j)

and FAP43-KO cells (Fig. 3a-e). Thus, the cilia targeting or docking of Fap57p does not depend upon the presence of Fap43p. In contrast to Fap57p, Fap44p-2V5 was not detected in cilia of FAP43 knockouts. Instead, this protein accumulated within the cell body (Fig. $3 g-j$ ). On the other hand, Fap44p-2V5, expressed in wild-type cells, was successfully targeted to cilia (Fig. 3f). Thus, Fap43p seems to be required for the targeting or docking of Fap44p to cilia. These observations were confirmed by mass spectrometry data, which showed that both Fap43p and Fap44p are absent from cilia purified from $F A P 43-K O$ cells (Table 2, Table S6).

\section{Lack of either Fap43p or Fap44p affects cilia beating in a similar way}

To further analyze the interdependence between Fap43p and Fap44p, we obtained somatic knockouts of FAP44 (Fig. S10) by targeted gene disruption in macronuclei (codeletion method, coDel) [43]. The phenotypic analysis showed that, similar to FAP43-KO cells, FAP44-KO cells 

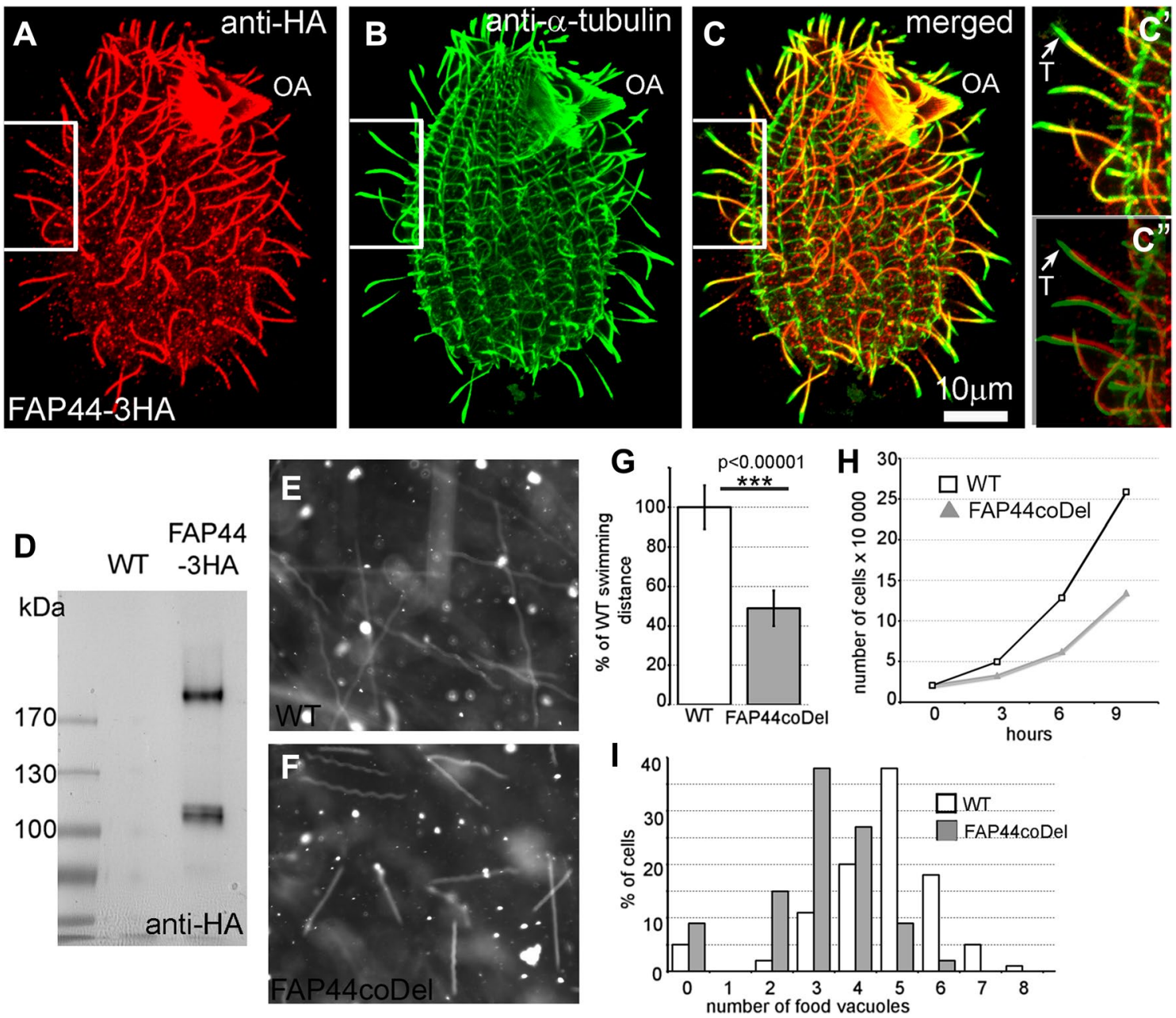

Fig. 4 Fap44p-3HA, similar to Fap43p localized throughout the cilia, except the cilia tips, and is indispensable for proper cilia function. a-c $\mathbf{c}^{\prime \prime}$ Immunofluorescence confocal images of Tetrahymena cells expressing Fap44p-3HA at the native level, double labeled with antiHA (a) and anti- $\alpha$-tubulin antibodies (b). $\mathbf{c}-\mathbf{c}^{\prime \prime}$ Merged images. $\mathbf{c}^{\prime}-\mathbf{c}^{\prime \prime}$ Magnifications of cilia marked with white insets in $\mathbf{a}-\mathbf{c}$. $\mathbf{c}^{\prime \prime}$ Note a shift in the merging of the $\mathbf{a}$ and $\mathbf{b}$ magnified images enabling better visualization of the cilia tips lacking Fap44p. $O A$ oral apparatus, $T$ cilium tip. Scale bar $10 \mu \mathrm{m}$. d Western blot analysis of ciliary proteins isolated from wild-type and Fap44p-3HA-expressing cells

exhibited alteration of cilia-dependent processes. Tetrahymena cells lacking Fap44p swam (Figs. 2a, 4e-g, Fig. S4, Supplemental Movie 5), proliferated (Fig. 4h) and formed vacuoles (Fig. 4i) at a lower rate than the wild-type cells. The waveform and amplitude of the beating cilia of FAP44$K O$ mutants were similar to those observed in FAP43-KO mutants, but we observed either immotile or rotating cilia even more frequently (Fig. 2b, Fig. S5, Supplemental Movie $6)$.

To investigate whether Fap44p is required for Fap43p ciliary localization, we introduced a transgene enabling the expression of Fap43p-2V5 under a FAP43 promoter into wild-type and FAP44 knockout cells. Whereas in the

stained with anti-HA antibodies. Swimming paths of wild-type (e) and FAP44coDel mutants (f) recorded for $3.2 \mathrm{~s}$ using a video camera. g Average distance swum during $3.2 \mathrm{~s}$, normalized to the wild-type value (WT, $n=139$; FAP44coDel, $n=146$ ). Bars represent standard deviation, $p$ value $<0.00001$. $\mathbf{h}$ Growth curves of wild-type and FAP$44 \mathrm{coDel}$ mutant cells. i Graph showing the efficiency of the formation of food vacuoles based on the analyses of the number of India ink-filled food vacuoles per cell formed during $10 \mathrm{~min}$. On average, wild-type and FAP44coDel cells formed 4.6 vacuoles ( $n=100$ cells) and 3.1 vacuoles ( $n=100$ cells), respectively

wild-type cells, the Fap43p-2V5 fusion protein was detected in cilia (Fig. 5a), in cells with deleted Fap44p, the cilia lacked Fap43p-2V5 (Fig. 5b-d). Thus, in Tetrahymena, Fap44p is required for Fap43p ciliary localization. Accordingly, Fap43p was absent in cilia purified from Tetrahymena FAP44 knockout mutants, as revealed by mass spectrometry analysis (Table 2, Table S6).

Similar localization experiments for Fap57p showed that Fap57Ap-2V5 was effectively targeted to cilia in wild-type and FAP44-KO coDel cells (Fig. 5e-h). Thus, it is most likely that Fap43p and Fap44p are subunits of the same ciliary complex, and their presence in cilia is interdependent, but neither of the proteins is required for ciliary localization of Fap57p. 
Table 2 Comparative proteomics of ciliary proteins in wild-type and FAP43 and FAP44 mutant cells

\begin{tabular}{lllll}
\hline Proteins & \multicolumn{4}{l}{ Number of unique peptides } \\
\cline { 2 - 5 } & WT & FAP43-KO & FAP43coDel & FAP44coDel \\
\hline Atu1 $\alpha$-tubulin & $2739 / 53$ & $1924 / 52$ & $2890 / 53$ & $2646 / 50$ \\
Btu1 $\beta$-tubulin & $3058 / 56$ & $2423 / 56$ & $2949 / 52$ & $3072 / 51$ \\
ODA Dyh3 & $1616 / 425$ & $1055 / 426$ & $1411 / 440$ & $877 / 261$ \\
ODA Dyh4 & $1702 / 448$ & $1127 / 424$ & $1395 / 445$ & $981 / 284$ \\
ODA Dyh5 & $1164 / 345$ & $906 / 355$ & $990 / 355$ & $701 / 225$ \\
IDA I1a Dyh6 & $440 / 234$ & $371 / 236$ & $377 / 222$ & $98 / 59$ \\
IDA I1b Dyh7 & $387 / 220$ & $356 / 252$ & $359 / 218$ & $86 / 61$ \\
Fap43 & $100 / 69$ & 0 & 0 & 0 \\
Fap44 & $88 / 64$ & 0 & 0 & 0 \\
Fap57A & $43 / 36$ & $43 / 36$ & $40 / 35$ & $21 / 20$ \\
Fap57B & $19 / 17$ & $29 / 26$ & $15 / 14$ & $9 / 9$ \\
Fap57C & $19 / 18$ & $12 / 12$ & $8 / 8$ & $5 / 5$ \\
\hline
\end{tabular}

Mass spectrometry analysis of the axonemal proteins from Tetrahymena wild-type, FAP43 knockout (FAP43-KO and FAP43coDel) and FAP44coDel mutant cells. The table shows the numbers $(\mathrm{X} / \mathrm{Y})$ of all the identified peptides $(\mathrm{X})$ and identified unique peptides $(\mathrm{Y})$. Note that Fap43p and Fap44p are missing in mutant but not in wild-type axonemes (all identified proteins are listed in Table S6)

\section{Ciliary beating is similarly affected in Dyh6p, Dyh7p, Fap43p and Fap44p mutants}

It is thought that the size and waveform of the ciliary bend are controlled by the inner dynein arms $[4,7]$. Some Dyh6p peptides were identified in the precipitates of biotinylated proteins from cilia of Fap43p-HA-BirA* or Fap44p-HA-BirA* expressing cells (Table 1, Tables S4, S5; in Tetrahymena, Dyh6 and Dyh7 are the dynein heavy chains of the two-headed inner dynein arm I1 (dynein $\mathrm{f}$ ) [59-61]). Thus, it is plausible that the Fap43p/Fap44pcontaining complex is positioned near the IDA I1 motor domains. Using the coDel approach, we engineered Tetrahymena knockout cells with a disruption of the DYH6 or $D Y H 7$ gene (Fig. S10). To ensure the specificity of the gene targeting, we rescued DYH6coDel and DYH7coDel mutants with approximately $3 \mathrm{~kb}$ PCR fragments containing part of the 5'UTR and ORF of DYH6 or DYH7, respectively (rescue experiment, Fig. S4e-h).

Next, we compared the swimming speed and cilia beating pattern of DYH6 and DYH7 knockout mutants with those of the FAP43 or FAP44 knockouts (Fig. 2, Fig. S4). Mutants lacking either Dyh6p or Dyh7p swam slowly and on average traveled $43 \pm 6$ and $39 \pm 8 \%$, respectively, of the distance swum at the same time by wild-type cells, i.e., approximately $10 \%$ less than the distance traveled by FAP43-KO and FAP44-KO mutants (Fig. 2a, Fig. S4, Supplemental Movie 7, 8). DYH6coDel and DYH7coDel rescued cells swam at a similar speed as the wild-type cells (Fig. 2a, Supplementary
Movie 9,10), strongly suggesting that we specifically deleted a fragment of the $D Y H 6$ or $D Y H 7$ gene, respectively.

The analysis of the ciliary waveform revealed that both the power and recovery strokes were incomplete in the DYH6 and DYH7 knockout mutants (Fig. 2b). However, we noticed that, similar to the case in FAP43-KO and FAP44$K O$ mutants, not all cilia beat in an identical way, with some being immotile or rotating, especially in $D Y H 7$ knockout mutants (Supplemental Movies 11, 12). Thus, the lack of IDA I1 dynein heavy chains affects cell motility more severely than the deletion of FAP43 or FAP44. Moreover, inner arm I1 dyneins are present in FAP43 and FAP44 mutant ciliary proteomes (Table 2, Table S6). Thus, we assume that the Fap43p-Fap44p complex is not required for IDA I1 docking but perhaps could regulate its activity.

Fap43p and Fap44p are essential for proper ciliary motility and function also in the unicellular green algae Chlamydomonas. Chlamydomonas mutant cells lacking either Fap43p (fap43) or Fap44p (fap44) (Fig. S11a, b) swam at a reduced speed compared to wild-type cells (Fig. S11d, e) and showed some alteration in flagella behavior (Supplemental Movies 13-15). In contrast to Tetrahymena, in Chlamydomonas Fap244p (identified only in the proteomes of Chlamydomonas and Volvox) coassembles with the Fap43p/Fap44p complex [62]. Mutant cells lacking Fap244p (fap244) swam with only a slightly reduced rate compared to wild-type cells (Figs. S11c, e). Thus, Fap43p and Fap $44 p$ perform an important function in both cilia and flagella, and their role is likely evolutionarily conserved.

\section{Discussion}

Genetic, proteomic and microscopic analyses conducted in the last few years have delivered a significant amount of new data that have expanded our knowledge about motile cilia structure and beating regulation. At the same time, we are only beginning to understand the complexity of the molecular mechanisms that regulate the function of these highly sophisticated cellular nanomachines. One of the obstacles to fully deciphering the molecular mechanisms that regulate cilia beating in time and space is insufficient knowledge about the ciliary proteome, as well as about the functions of and interactions among the proteins that build cilia. It is estimated that cilia are composed of hundreds of proteins [20,21]. However, numerous proteins of the cilia proteome are only hypothetical ciliary proteins, and their precise localization in cilia and their roles are unknown. At the same time, cryo-electron tomography analyses and 3D reconstruction of the 96- $\mathrm{nm}$ axonemal unit revealed the existence of as-yet uncharacterized minor complexes of unknown protein composition and function. It is likely that these minor complexes function in signal transduction from the central pair complex to the dynein motors or regulate the functions of the major ciliary complexes. 


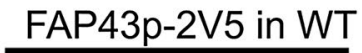

FAP43p-2V5 in FAP44 coDel
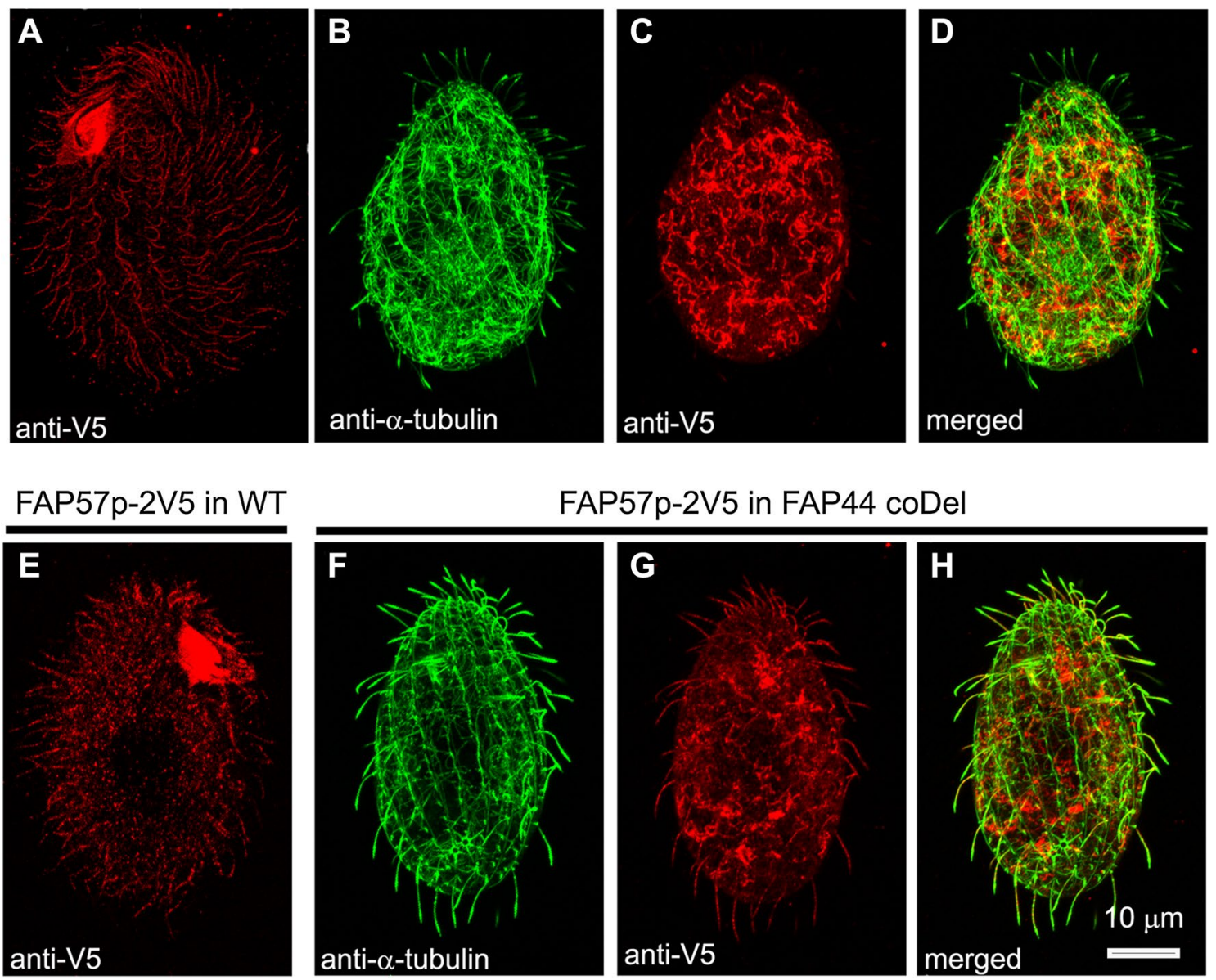

FAP57p-2V5 in FAP44 coDel

Fig. 5 Fap44p is indispensable for Fap43p but not Fap57p ciliary localization. Immunofluorescence confocal images of either wild-type (a, e) or FAP44 coDel Tetrahymena cells (b-d, $\mathbf{f}-\mathbf{h})$ expressing either

Searching for "missing links" in the chains of interacting proteins that are involved in cilia beating regulation, we focused our attention on the orthologs of two highly evolutionarily conserved ciliary proteins, Fap43p and Fap44p. We showed that both proteins likely form a minor ciliary complex and that they are essential for proper ciliary and flagellar beating. The biochemical analyses suggested that the Fap43p/Fap44p complex may be located in close proximity to IDA I1. Dyh6p, the 1-alpha DHC of IDA I1, was identified among the biotinylated proteins in cells expressing either Fap43p-BirA* or Fap44p-BirA*. However, the number of Dyh6p-specific peptides was low, suggesting that the distance between IDA I1 and the C-terminal end of Fap43p and Fap44p could be approximately $10 \mathrm{~nm}$ or slightly more, or that this distance could vary and that the motor domain of IDA I1 is only temporarily in the range of the BirA* ligase. Interestingly, cryo-electron tomography of axonemes isolated from wild-type Chlamydomonas revealed that one of the minor complexes of yet undetermined protein composition is positioned proximally to IDA I1 [13].

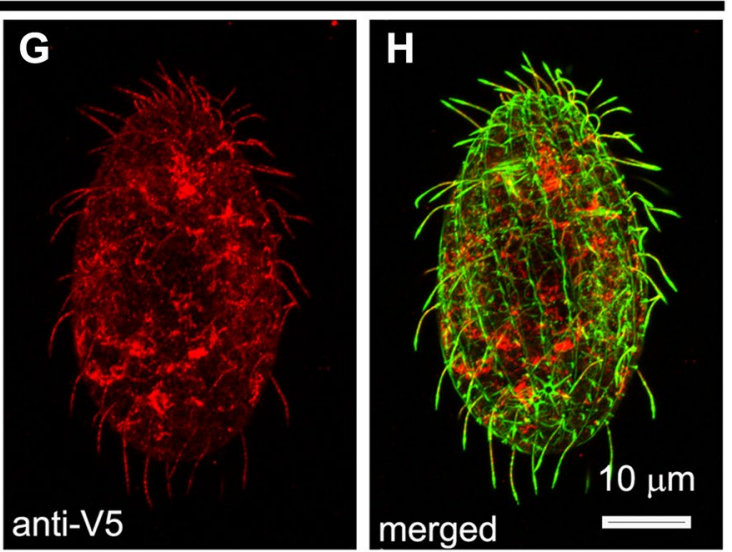

Fap43p-2V5 (a-d) or FAP57-2V5 (e-h) under the control of their native promoters, labeled with anti-V5 (a, c, e, g) and anti- $\alpha$-tubulin antibodies (b, f). d, $\mathbf{h}$ Merged images

This so-called tether/tether head complex seems to connect the IDA I $1 \alpha$ motor domain to the A-tubule of the outer doublet and was suggested to function as a sensor of the distance between the IDA I1 $\alpha$ motor domain and the microtubule surface [13]. It is possible that Fap43p/Fap44p are subunits of the tether/tether head complex. This assumption is supported by data obtained during the cryo-electron tomography analyses of the axonemes isolated from Tetrahymena FAP43 knockout cells showing that tether/tether head complex is missing in this mutant [62].

The mass spectrometry analyses of the entire cilia proteome indicated that Dyh6p and Dyh7p, which build the IDA I1 $\alpha$ and IDA I1 $\beta$ motor domains, respectively [59-61], are present in FAP43 and FAP44 knockout mutants. Thus, based on the data presented here, we hypothesize that the Fap43p/Fap44p complex is not required for IDA I1 assembly or docking to the axoneme. This conclusion is also supported by cryo-ET data of axonemes isolated from the FAP43-KO mutant, which showed that the IDA I1 complex is present in the majority of the axonemal units [62]. We speculate that the Fap43p/Fap44p complex 
could interact with IDA I1 and affect its motor activity. Such interactions could be regulated by, for example, the posttranslational modification of Fap43p. We detected two co-migrating bands of Fap43p-3HA on a western blot, which suggests either an alternative splicing of FAP43 or posttranslational modification of Fap43p. Because alternative splicing is infrequent in Tetrahymena [53, 54], the posttranslational modification of Fap43p is more plausible; such modifications could affect the properties of Fap43p and subsequently its interactions with IDA I1.

Based on the biochemical analyses, both Fap43p and Fap44p are positioned near the evolutionarily conserved yet uncharacterized protein Fap57. The Tetrahymena genome encodes at least four proteins with homology to Chlamydomonas Fap57, but only one of the Tetrahymena orthologs, Fap57A, predominates among ciliary proteins biotinylated in cells expressing either Fap43-HA-BirA* or Fap44-HA-BirA*. Because cryo-electron tomography analyses revealed that the entire tether/tether head complex is missing in Tetrahymena FAP43-KO cells [62] and Fap57Ap is present in cilia even in the absence of either Fap43p or Fap44p, it is likely that Fap57Ap, unlike Fap43p and Fap44p, is not a subunit of the tether/tether head complex but could form a linker between Fap43p/Fap44p complex and other axonemal macrocomplexes.

The overexpressed GFP-Fap43p not only localized to cilia but also accumulated near the basal bodies and co-immunoprecipitated with nucleoporins (Nup93, Nup155 and Nup308), kinesin type II and the dynein heavy chains of the outer dynein arms (Table S2). In mammalian cells, nucleoporins were detected at the cilium base $[63,64]$. Additionally, preassembled ODA and kinesin II-type motor protein accumulate near the ciliary base to be transported into the cilium. Because neither nucleoporins nor outer arm dyneins were identified as potential Fap43p partners when Fap43p was expressed at the native level and purified from cilia (Table 1, Tables S3, S4), we concluded that these proteins are not true Fap43p interactors.

Both Fap43p and Fap44p share similar domain organization; the N-terminal half is enriched in WD repeats, while the $\mathrm{C}$-terminal half is predicted to form several coiled-coils. When overexpressed as truncated fragments, only the C-terminal fragment localized to cilia and near the basal bodies, whereas the N-terminal WD40-repeat-containing fragments accumulated in the cell body and were most likely degraded. Thus, the C-terminal fragment of both Fap43p and Fap44p is required and sufficient for ciliary transport and localization.

Most axonemal proteins are delivered to cilia as cargo by intraflagellar transport (IFT) particles. However, with a few exceptions, it remains unknown which IFT subunit(s) mediates the transport of axonemal proteins and whether the cargo binds directly to the IFT subunit or requires an adaptor protein. Previously, it has been suggested that coiled-coils mediate the interactions between IFT subunits [65], but to our knowledge, there are no data showing interactions between IFT subunits and cargo involving coiled-coils. It is also possible that only a fragment of the C-terminal part of Fap43p or Fap44p mediates IFT subunit or adaptor protein recognition and binding. Further analyses are required to uncover the molecular mechanism underlying Fap43p and Fap44p ciliary transport.

Recent whole-exome sequencing of men with MMAF (multiple morphological abnormalities of the flagella) revealed that biallelic mutations in CFAP43 and CFAP44 result in diverse morphological sperm defects and male infertility [66]. It is plausible that mutations in Fap43p or Fap44p could also affect the function of motile cilia assembled in different organs and not only in sperm cells. In humans, coordinated ciliary beating drives, e.g., cleaning of the airways, circulation of the cerebrospinal fluid in the brain ventricles and transport of oocytes in the Fallopian tubes prior to fertilization. The movement of the nodal cilia ensures proper left-right asymmetry of the internal organs in the human body. Defects in the assembly or function of the motile cilia cause a multisymptomatic, genetically heterogeneous disorder called primary ciliary dyskinesia (PCD), which affects one per 15,000-30,000 individuals [67-70]. Interestingly, the genetic background of many recognized cases of PCD remains unknown. Since Fap43p and Fap44p are indispensable for proper cilia beating in Tetrahymena and both proteins are highly evolutionarily conserved, it is plausible that mutations in either FAP43 or FAP44 may cause PCD. Thus, Fap43p and Fap44p could be new candidate protein markers for PCD or other ciliopathies.

Acknowledgements We are very grateful to the following persons, who helped us in this research: Henryk Bilski and Szymon Suski from the Laboratory of Electron Microscopy of the Nencki Institute; Tytus Bernas, Artur Wolny and Malgorzata Calka, the members of the Laboratory of Imaging Tissue Structure and Function of the Nencki Institute, for their help in visualization of cilia beating; Dr. Jacek Gaertig, for providing the plasmid containing a coding region of Tetrahymena codon optimized BirA*; Dr. Tokuko Haraguchi, for providing the plasmid with the pur4 cassette; and Dr. Kazufumi Mochizuki, for providing the pMcoDel vector. The mass spectrometry analyses were performed in the Mass Spectrometry Laboratory, Institute of Biochemistry and Biophysics, PAS, Warsaw, Poland. The monoclonal anti- $\alpha$-tubulin 12G10 antibody, developed by J. Frankel and E. M. Nelsen, was obtained from the Developmental Studies Hybridoma Bank developed under the auspices of the NICHD and maintained by the University of Iowa, Department of Biology, Iowa City, IA 52242. This research was supported by the following grants: Polish Ministry of Science and Higher Education Grant no. N301706640, National Science Centre, Poland 2014/14/M/NZ3/00511 (Harmonia 6) grant and EMBO Installation Grant no. 2331 to DW; National Science Centre, Poland 2014/13/N/NZ3/04612 Preludium 7 grant to PU; and National Institutes of Health award R01 GM083122 to DN

Open Access This article is distributed under the terms of the Creative Commons Attribution 4.0 International License (http://creativeco mmons.org/licenses/by/4.0/), which permits unrestricted use, distribution, and reproduction in any medium, provided you give appropriate credit to the original author(s) and the source, provide a link to the Creative Commons license, and indicate if changes were made. 


\section{References}

1. Goodenough UW, Heuser JE (1985) Substructure of inner dynein arms, radial spokes, and the central pair/projection complex of cilia and flagella. J Cell Biol 100(6):2008-2018

2. Nicastro D, Schwartz C, Pierson J, Gaudette R, Porter ME, McIntosh JR (2006) The molecular architecture of axonemes revealed by cryoelectron tomography. Science 313(5789):944-948

3. Yamamoto R, Song K, Yanagisawa HA, Fox L, Yagi T, Wirschell M, Hirono M, Kamiya R, Nicastro D, Sale WS (2013) The MIA complex is a conserved and novel dynein regulator essential for normal ciliary motility. J Cell Biol 201(2):263-278

4. Brokaw CJ, Kamiya R (1987) Bending patterns of Chlamydomonas flagella: IV. Mutants with defects in inner and outer dynein arms indicate differences in dynein arm function. Cell Motil Cytoskelet 8(1):68-75

5. Porter ME, Power J, Dutcher SK (1992) Extragenic suppressors of paralyzed flagellar mutations in Chlamydomonas reinhardtii identify loci that alter the inner dynein arms. J Cell Biol 118(5):1163-1176

6. Bui KH, Sakakibara H, Movassagh T, Oiwa K, Ishikawa T (2008) Molecular architecture of inner dynein arms in situ in Chlamydomonas reinhardtii flagella. J Cell Biol 183(5):923-932

7. King SM, Kamiya R (2009) Axonemal dyneins: assembly, structure, and force generation, second edn. In: Witman GB (ed) The Chlamydomonas sourcebook: cell motility and behavior, vol 3 . Academic Press, San Diego, pp 131-208

8. Bui KH, Yagi T, Yamamoto R, Kamiya R, Ishikawa T (2012) Polarity and asymmetry in the arrangement of dynein and related structures in the Chlamydomonas axoneme. J Cell Biol 198(5):913-925

9. Kamiya R, Yagi T (2014) Functional diversity of axonemal dyneins as assessed by in vitro and in vivo motility assays of Chlamydomonas mutants. Zool Sci 31(10):633-644

10. Kotani N, Sakakibara H, Burgess SA, Kojima H, Oiwa K (2007) Mechanical properties of inner-arm dynein-f (dynein I1) studied with in vitro motility assays. Biophys J 93(3):886-894

11. Toba S, Fox LA, Sakakibara H, Porter ME, Oiwa K, Sale WS (2011) Distinct roles of 1alpha and 1beta heavy chains of the inner arm dynein I1 of Chlamydomonas flagella. Mol Biol Cell 22(3):342-353

12. Mastronarde DN, O' Toole ET, McDonald KL, McIntosh JR, Porter ME (1992) Arrangement of inner dynein arms in wild-type and mutant flagella of Chlamydomonas. J Cell Biol 118(5):1145-1162

13. Heuser T, Barber CF, Lin J, Krell J, Rebesco M, Porter ME, Nicastro D (2012) Cryoelectron tomography reveals doublet-specific structures and unique interactions in the I1 dynein. Proc Natl Acad Sci USA 109(30):E2067-E2076

14. Oda T, Yagi T, Yanagisawa H, Kikkawa M (2013) Identification of the outer-inner dynein linker as a hub controller for axonemal dynein activities. Curr Biol 23(8):656-664

15. Porter ME, Sale WS (2000) The $9+2$ axoneme anchors multiple inner arm dyneins and a network of kinases and phosphatases that control motility. J Cell Biol 151(5):F37-F42

16. Smith EF, Yang P (2004) The radial spokes and central apparatus: mechano-chemical transducers that regulate flagellar motility. Cell Motil Cytoskelet 57(1):8-17

17. Wirschell M, Hendrickson T, Sale WS (2007) Keeping an eye on I1: I1 dynein as a model for flagellar dynein assembly and regulation. Cell Motil Cytoskelet 64(8):569-579

18. Smith EF (2002) Regulation of flagellar dynein by the axonemal central apparatus. Cell Motil Cytoskelet 52(1):33-42

19. Kamiya R (2002) Functional diversity of axonemal dyneins as studied in Chlamydomonas mutants. Int Rev Cytol 219:115-155
20. Li JB, Gerdes JM, Haycraft CJ, Fan Y, Teslovich TM, May-Simera $\mathrm{H}$, Li H, Blacque OE, Li L, Leitch CC, Lewis RA, Green JS, Parfrey PS, Leroux MR, Davidson WS, Beales PL, Guay-Woodford LM, Yoder BK, Stormo GD, Katsanis N, Dutcher SK (2004) Comparative genomics identifies a flagellar and basal body proteome that includes the BBS5 human disease gene. Cell 117(4):541-552

21. Pazour GJ, Agrin N, Leszyk J, Witman GB (2005) Proteomic analysis of a eukaryotic cilium. J Cell Biol 170(1):103-113

22. Bui KH, Pigino G, Ishikawa T (2011) Three-dimensional structural analysis of eukaryotic flagella/cilia by electron cryo-tomography. J Synchrotron Radiat 18(1):2-5

23. Nicastro D, Fu X, Heuser T, Tso A, Porter ME, Linck RW (2011) Cryo-electron tomography reveals conserved features of doublet microtubules in flagella. Proc Natl Acad Sci USA 108(42):E845-E853

24. Pigino G, Bui KH, Maheshwari A, Lupetti P, Diener D, Ishikawa T (2011) Cryoelectron tomography of radial spokes in cilia and flagella. J Cell Biol 195(4):673-687

25. Pigino G, Maheshwari A, Bui KH, Shingyoji C, Kamimura S, Ishikawa T (2012) Comparative structural analysis of eukaryotic flagella and cilia from Chlamydomonas, Tetrahymena, and sea urchins. J Struct Biol 178(2):199-206

26. Carbajal-Gonzalez BI, Heuser T, Fu X, Lin J, Smith BW, Mitchell DR, Nicastro D (2013) Conserved structural motifs in the central pair complex of eukaryotic flagella. Cytoskeleton (Hoboken) 70:101-120

27. Dymek EE, Smith EF (2007) A conserved CaM- and radial spoke associated complex mediates regulation of flagellar dynein activity. J Cell Biol 179(3):515-526

28. Dymek EE, Heuser T, Nicastro D, Smith EF (2011) The CSC is required for complete radial spoke assembly and wild-type ciliary motility. Mol Biol Cell 22(14):2520-2531

29. Heuser T, Dymek EE, Lin J, Smith EF, Nicastro D (2012) The CSC connects three major axonemal complexes involved in dynein regulation. Mol Biol Cell 23(16):3143-3155

30. Urbanska P, Song K, Joachimiak E, Krzemien-Ojak L, Koprowski P, Hennessey T, Jerka-Dziadosz M, Fabczak H, Gaertig J, Nicastro D, Wloga D (2015) The CSC proteins FAP61 and FAP251 build the basal substructures of radial spoke 3 in cilia. Mol Biol Cell 26(8):1463-1475

31. Gorovsky MA, Yao MC, Keevert JB, Pleger GL (1975) Isolation of micro- and macronuclei of Tetrahymena pyriformis. Methods Cell Biol 9:311-327

32. Subramanian A, Kabi A, Gray SF, Pennock D (2016) p28 dynein light chains and ciliary motility in Tetrahymena thermophila. Cytoskeleton (Hoboken) 73(4):197-208

33. Zhang R, Patena W, Armbruster U, Gang SS, Blum SR, Jonikas MC (2014) High-throughput genotyping of green algal mutants reveals random distribution of mutagenic insertion sites and endonucleolytic cleavage of transforming DNA. Plant Cell 26(4):1398-1409

34. Li X, Zhang R, Patena W, Gang SS, Blum SR, Ivanova N, Yue R, Robertson JM, Lefebvre PA, Fitz-Gibbon ST, Grossman AR, Jonikas MC (2016) An indexed, mapped mutant library enables reverse genetics studies of biological processes in Chlamydomonas reinhardtii. Plant Cell 28(2):367-387

35. Waclawek E, Joachimiak E, Hall MH, Fabczak H, Wloga D (2017) Regulation of katanin activity in the ciliate Tetrahymena thermophila. Mol Microbiol 103(1):134-150

36. Mochizuki K (2008) High efficiency transformation of Tetrahymena using a codon-optimized neomycin resistance gene. Gene 425:79-83

37. Iwamoto M, Mori C, Hiraoka Y, Haraguchi T (2014) Puromycin resistance gene as an effective selection marker for ciliate Tetrahymena. Gene 534(2):249-255 
38. Wloga D, Camba A, Rogowski K, Manning G, Jerka-Dziadosz M, Gaertig J (2006) Members of the NIMA-related kinase family promote disassembly of cilia by multiple mechanisms. Mol Biol Cell 17(6):2799-2810

39. Gaertig J, Gu L, Hai B, Gorovsky MA (1994) High frequency vector-mediated transformation and gene replacement in Tetrahymena. Nucleic Acids Res 22:5391-5398

40. Bregier C, Krzemień-Ojak L, Włoga D, Jerka-Dziadosz M, Joachimiak E, Batko K, Filipiuk I, Smietanka U, Gaertig J, Fabczak S, Fabczak H (2013) PHLP2 is essential and plays a role in ciliogenesis and microtubule assembly in Tetrahymena thermophila. J Cell Physiol 228(11):2175-2189

41. Cassidy-Hanley D, Bowen J, Lee JH, Cole E, VerPlank LA, Gaertig J, Gorovsky MA, Bruns PJ (1997) Germline and somatic transformation of mating Tetrahymena thermophila by particle bombardment. Genetics 146(1):135-147

42. Dave D, Wloga D, Gaertig J (2009) Manipulating ciliary proteinencoding genes in Tetrahymena thermophila. Methods Cell Biol 93:1-20

43. Hayashi A, Mochizuki K (2015) Targeted gene disruption by ectopic induction of DNA elimination in Tetrahymena. Genetics 201(1):55-64

44. Gibson DG (2011) Enzymatic assembly of overlapping DNA fragments. Methods Enzymol 498:349-361

45. Wloga D, Rogowski K, Sharma N, Van Dijk J, Janke C, Eddé B, Bré MH, Levilliers N, Redeker V, Duan J, Gorovsky MA, JerkaDziadosz M, Gaertig J (2008) Glutamylation on alpha-tubulin is not essential but affects the assembly and functions of a subset of microtubules in Tetrahymena thermophila. Eukaryot Cell 7(8):1362-1372

46. Janke C, Rogowski K, Wloga D, Regnard C, Kajava AV, Strub JM, Temurak N, van Dijk J, Boucher D, van Dorsselaer A, Suryavanshi S, Gaertig J, Eddé B (2005) Tubulin polyglutamylase enzymes are members of the TTL domain protein family. Science 308(5729): 1758-1762

47. Jeanmougin F, Thompson JD, Gouy M, Higgins DG, Gibson TJ (1998) Multiple sequence alignment with Clustal X. Trends Biochem Sci 23(10):403-405

48. Galtier N, Gouy M, Gautier C (1996) SEAVIEW and PHYLO_ WIN: two graphic tools for sequence alignment and molecular phylogeny. Comput Appl Biosci 12(6):543-548

49. Wu XH, Wang Y, Zhuo Z, Jiang F, Wu YD (2012) Identifying the hotspots on the top faces of WD40-repeat proteins from their primary sequences by beta-bulges and DHSW tetrads. PLoS One 7(8):e43005

50. Wang Y, Jiang F, Zhuo Z, Wu XH, Wu YD (2013) A method for WD40 repeat detection and secondary structure prediction. PLoS One 8(6):e65705

51. Wang Y, Hu XJ, Zou XD, Wu XH, Ye ZQ, Wu YD (2015) WDSPdb: a database for WD40-repeat proteins. Nucleic Acids Res 43:D339-D344

52. Lupas A, Van Dyke M, Stock J (1991) Predicting coiled coils from protein sequences. Science 252:1162-1164

53. Coyne RS, Thiagarajan M, Jones KM, Wortman JR, Tallon LJ, Haas BJ, Cassidy-Hanley DM, Wiley EA, Smith JJ, Collins K, Lee SR, Couvillion MT, Liu Y, Garg J, Pearlman RE, Hamilton EP, Orias E, Eisen JA, Methé BA (2008) Refined annotation and assembly of the Tetrahymena thermophila genome sequence through EST analysis, comparative genomic hybridization, and targeted gap closure. BMC Genom 9:562

54. Xiong J, Lu X, Zhou Z, Chang Y, Yuan D, Tian M, Zhou Z, Wang L, Fu C, Orias E, Miao W (2012) Transcriptome analysis of the model protozoan, Tetrahymena thermophila, using Deep RNA sequencing. PLoS One 7(2):e30630
55. Shang Y, Song X, Bowen J, Corstanje R, Gao Y, Gaertig J, Gorovsky MA (2002) A robust inducible-repressible promoter greatly facilitates gene knockouts, conditional expression, and overexpression of homologous and heterologous genes in Tetrahymena thermophila. Proc Natl Acad Sci USA 99(6):3734-3739

56. Brown JM, Hardin C, Gaertig J (1999) Rotokinesis, a novel phenomenon of cell locomotion-assisted cytokinesis in the ciliate Tetrahymena thermophila. Cell Biol Int 23(12):841-848

57. Nilsson JR (1979) Phagotrophy in Tetrahymena. In: Levandowsky M, Hutner SH (eds) Biochemistry and physiology of protozoa, vol 2. Academic Press, New York, pp 329-379

58. Roux KJ, Kim DI, Raida M, Burke B (2012) A promiscuous biotin ligase fusion protein identifies proximal and interacting proteins in mammalian cells. J Cell Biol 196(6):801-810

59. Angus SP, Edelmann RE, Pennock DG (2001) Targeted gene knockout of inner arm 1 in Tetrahymena thermophila. Eur J Cell Biol 80(7):486-497

60. Hennessey TM, Kim DY, Oberski DJ, Hard R, Rankin SA, Pennock DG (2002) Inner arm dynein 1 is essential for $\mathrm{Ca}++$-dependent ciliary reversals in Tetrahymena thermophila. Cell Motil Cytoskelet 53(4):281-288

61. Wood CR, Hard R, Hennessey TM (2007) Targeted gene disruption of dynein heavy chain 7 of Tetrahymena thermophila results in altered ciliary waveform and reduced swim speed. J Cell Sci 120(Pt 17):3075-3085

62. Fu G, Wang Q, Phan N, Urbanska P, Joachimiak E, Lin J, Wloga D, Nicastro D (2018) The I1 dynein-associated tether and tether head complex is a conserved regulator of ciliary motility. Mol Biol Cell. https://doi.org/10.1091/mbc.e18-02-0142

63. Kee HL, Dishinger JF, Blasius TL, Liu CJ, Margolis B, Verhey KJ (2012) A size-exclusion permeability barrier and nucleoporins characterize a ciliary pore complex that regulates transport into cilia. Nat Cell Biol 14(4):431-437

64. Del Viso F, Huang F, Myers J, Chalfant M, Zhang Y, Reza N, Bewersdorf J, Lusk CP, Khokha MK (2016) Congenital heart disease genetics uncovers context-dependent organization and function of nucleoporins at cilia. Dev Cell 38(5):478-492

65. Taschner M, Bhogaraju S, Lorentzen E (2012) Architecture and function of IFT complex proteins in ciliogenesis. Differentiation 83(2):S12-S22

66. Tang S, Wang X, Li W, Yang X, Li Z, Liu W, Li C, Zhu Z, Wang L, Wang J, Zhang L, Sun X, Zhi E, Wang H, Li H, Jin L, Luo Y, Wang J, Yang S, Zhang F (2017) Biallelic mutations in CFAP43 and CFAP44 cause male infertility with multiple morphological abnormalities of the sperm flagella. Am J Hum Genet 100(6):854-864

67. Afzelius BA (1998) Genetics and pulmonary medicine. 6. Immotile cilia syndrome: past, present, and prospects for the future. Thorax 53(10):894-897

68. Bush A, Cole P, Hariri M, Mackay I, Phillips G, O’Callaghan C, Wilson R, Warner JO (1998) Primary ciliary dyskinesia: diagnosis and standards of care. Eur Respir J 12(4):982-988

69. Barbato A, Frischer T, Kuehni CE, Snijders D, Azevedo I, Baktai G, Bartoloni L, Eber E, Escribano A, Haarman E, Hesselmar B, Hogg C, Jorissen M, Lucas J, Nielsen KG, O’Callaghan C, Omran H, Pohunek P, Strippoli MP, Bush A (2009) Primary ciliary dyskinesia: a consensus statement on diagnostic and treatment approaches in children. Eur Respir J 34(6):1264-1276

70. Horani A, Brody SL, Ferkol TW (2014) Picking up speed: advances in the genetics of primary ciliary dyskinesia. Pediatr Res 75(1-2):158-164 